\title{
Changes in the enterocyte cytoskeleton in newborn rats exposed to ethanol in utero
}

\author{
J F Montes, G Estrada, M D López-Tejero, J García-Valero
}

\begin{abstract}
Background-Cytoskeletal changes after longterm exposure to ethanol have been described in a number of cell types in adult rat and humans. These changes can play a key part in the impairment of nutrient assimilation and postnatal growth retardation after prenatal damage of the intestinal epithelium produced by ethanol intake.

Aims-To determine, in the newborn rat, which cytoskeletal proteins are affected by longterm ethanol exposure in utero and to what extent.
\end{abstract}

Animals-The offspring of two experimental groups of female Wistar rats: ethanol treated group receiving up to $25 \%$ (w/v) of ethanol in the drinking fluid and control group receiving water as drinking fluid.

Methods-Single and double electron microscopy immunolocalisation and label density estimation of cytoskeletal proteins on sections of proximal small intestine incubated with monoclonal antibodies against actin, $\alpha$-tubulin, cytokeratin (polypeptides 1, 5, 6, 7, 8, 10, 11, and 18), and with a polyclonal antibody anti- $\beta$ 1,4-galactosyl transferase as trans golgi (TG) or trans golgi network (TGN) marker, or both. SDS-PAGE technique was also performed on cytoskeletal enriched fractions from small intestine. Western blotting analysis was carried out by incubation with the same antibodies used for immunolocalisation.

Results-Intestinal epithelium of newborn rats from the ethanol treated group showed an overexpression of cytoskeletal polypeptides ranging from 39 to $54 \mathrm{kDa}$, affecting actin and some cytokeratins, but not tubulin. Furthermore, a cytokeratin related polypeptide of 28-29 kDa was identified together with an increase in free ubiquitin in the same group. It was noteworthy that actin and cytokeratin were abnormally located in the TG or the TGN, or both.

Conclusions-Longterm exposure to ethanol in utero causes severe dysfunction in the cytoskeleton of the developing intestinal epithelium. Actin and cytokeratins, which are involved in cytoskeleton anchoring to plasma membrane and cell adhesion, are particularly affected, showing overexpression, impaired proteolysis, and mislocalisation.

(Gut 1996; 38: 846-852)

Keywords: actin, cytokeratin, fetal alcohol syndrome, trans golgi network, tubulin, ubiquitin.
Longterm exposure to ethanol in utero results in postnatal growth retardation in the rat, ${ }^{1}$ which could be related to prenatal damage ${ }^{2} 3$ induced by the high ethanol concentration found in the fetal gastrointestinal lumen. ${ }^{4}$ However, the mechanism by which ethanol impairs nutrient assimilation in the neonates is not well characterised. Enteral nutrition is critically dependent on the functioning of intestinal epithelium, based on (a) the organisation of membrane domains, (b) the transport pathways across these membranes, and (c) the maintenance of epithelial sheet integrity by cell adhesion. Appropriate nutrient transport in epithelial cells requires the development and maintenance of precise and polarised distributions of proteins and lipids, as well as the organisation and maintenance of specialised cell-cell and cell-substratum contacts. ${ }^{5-7}$

Ethanol and its metabolic derivatives interact with proteins and lipids, modifying their functional properties. Several ethanol induced molecular and cellular phenomena have been described in alcoholic adults and cell cultures, such as decreased membrane bound enzyme activities, ${ }^{89}$ intracellular accumulation of secretion proteins, ${ }^{9} 10$ changed gene expression, ${ }^{10-13}$ inhibition of proteolysis, ${ }^{14}$ covalent binding with lipids ${ }^{15-17}$ and proteins, ${ }^{18} 19$ and inhibition of cell-cell adhesion. ${ }^{20}$ As cytoskeletal integrity is a prerequisite for many of these cell functions, several authors have investigated the interactions between ethanol and the cytoskeletal proteins. ${ }^{21} 22$ Pinazo-Durán et $a^{23}$ found ethanol induced changes in cytoskeletal proteins such as GFAP in astrocytes, with occasional disorganisation of the entire cytoskeleton. Reddy et al ${ }^{8}$ reported changes in actin associated proteins such as myosin and Adickes et $a l^{24}$ described cytoskeletal dysgenesis in myocytes. So far, the ethanol induced changes seen in actin cytoskeleton have been related to acetaldehyde, the main metabolite of ethanol oxidation, as studies carried out in vitro by $\mathrm{Xu}$ et $a l^{18}$ reported that $\mathrm{G}$ actin forms stable covalent adducts with acetaldehyde.

Given the significance of the cytoskeleton for enterocyte function at birth, and its importance to postnatal nutrition in mammals, the aim of this study is to determine in the newborn rat which cytoskeletal proteins are affected by longterm ethanol exposure in utero and to what extent.

\section{Methods}

Animals and treatments

The experiments were performed on the offspring of female Wistar rats from our own

Spain. 


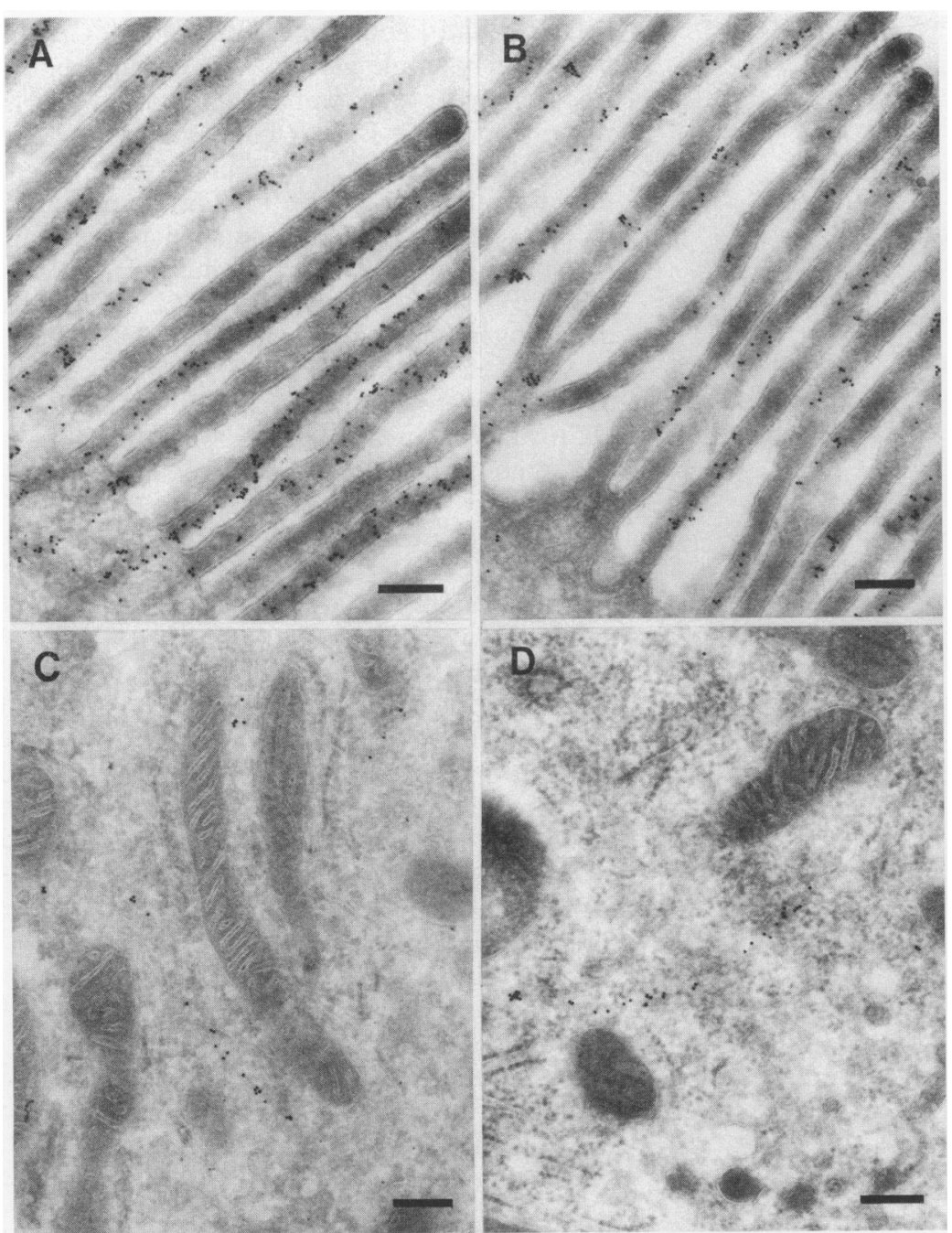

Figure 1: Actin immunolocalisation in the microvillus domain of control $(A, \times 58000)$ and prenatally ethanol exposed enterocytes $(B, \times 52$ 000). Tubulin immunolocalisation in the cytoplasm of control $(C, \times 52000)$ and prenatally ethanol exposed enterocytes (D, $\times 54$ 000). Bars $=5 \mu \mathrm{m}$. and the total small intestine (from the pylorus to the ileocaecal junction) was perfused gently, in situ, with cold $\mathrm{NaCl} 0.9 \%$ solution. The proximal small intestine (duodenum and proximal jejunum) were cut into small blocks of tissue and were fixed in $4 \%(\mathrm{w} / \mathrm{v})$ paraformaldehyde and $0.1 \%(\mathrm{v} / \mathrm{v})$ glutaraldehyde in $0.1 \mathrm{M}$ phosphate buffered saline (PBS), $\mathrm{pH} 7 \cdot 4$, for two hours at $4^{\circ} \mathrm{C}$. The samples were then cryoprotected by infusion with $2 \cdot 1 \mathrm{M}$ sucrose in PBS, mounted, and frozen in liquid nitrogen. Ultrathin cryosections were obtained using a cryo system (Reichert FC-40) and transferred to grids in a drop of $2.3 \mathrm{M}$ sucrose in PBS.

Before labelling, sections were rinsed twice with $0 \cdot 1 \mathrm{M}$ glycine in PBS (gly PBS) for 10 minutes and incubated with $2 \%$ ovalbumin in PBS for 20 minutes. For single immunolabelling, ${ }^{26}$ the grids were incubated during 30 minutes with monoclonal antibodies (mAbs) against $\alpha$-tubulin (Amersham, Arlington Heights, IL), cytokeratin (polypeptides 1, 5, 6, 7 , and 8 of the basic and 10,11, and 18 of the acidic cytokeratins; ICN Biomedicals, Costa Mesa, CA), actin (Amersham), and with a polyclonal anti- $\beta$ 1,4-galactosyl transferase serum (gift of Dr S Vilaró, Facultat de Biologia, Barcelona). After washing three times with gly PBS for 15 minutes, bound mAbs were visualised with $10 \mathrm{~nm}$ colloidal gold conjugated goat antimouse Ig (Amersham) and bound anti- $\beta$ 1,4-galactosyl transferase serum was detected with $10 \mathrm{~nm}$ protein A gold (pAg) (Sigma Chemical, St Louis, MO). For double immunolabelling, ${ }^{27}$ sections were first labelled for anti- $\beta$ 1,4-galactosyl transferase serum with $10 \mathrm{~nm}$ pAg, then stabilised with $1 \%$ glutaraldehyde in PBS for five minutes, and incubated with the mAbs against actin or cytokeratin followed by unlabelled rabbit antimouse Ig (Amersham) and detected with $16 \mathrm{~nm}$ pAg (Sigma). The ultrathin cryosections were rinsed with PBS and double-distilled water before staining with uranyl acetate and embedding in methyl cellulose. ${ }^{28}$ Observations were carried out with a Hitachi H-600 AB transmission electron microscope.

\section{Quantitative evaluation}

Label density was estimated as the number of gold particles either per area of compartment

Label density expressed as number of gold particles ( $g p$ ) per unit length or area for $\alpha$-tubulin, actin, and cytokeratin of several cell compartment

\begin{tabular}{|c|c|c|}
\hline & Control group & $\begin{array}{l}\text { Ethanol treated } \\
\text { group }\end{array}$ \\
\hline Tubulin & & \\
\hline Cytoplasm (gp/ $\left./ \mu \mathrm{m}^{2}\right)$ & $7 \cdot 63(1 \cdot 10)$ & $11 \cdot 46(0.74)$ \\
\hline $\begin{array}{l}\text { Actin } \\
\text { Microvilli }\left(\mathrm{gp} / \mu \mathrm{m}^{2}\right)\end{array}$ & $95.22(10 \cdot 24)$ & $121 \cdot 43(7 \cdot 30)$ \\
\hline $\begin{array}{l}\text { Lateral interdigitations } \\
(\mathrm{gp} / \mu \mathrm{m})\end{array}$ & $2.48(0.24)$ & $4.76(0.83)^{\star \star}$ \\
\hline Vesicles $(\mathrm{gp} / \mu \mathrm{m})$ & $1.75(0.23)$ & $12 \cdot 13(1 \cdot 38)^{\star \star}$ \\
\hline Cytokeratin & & \\
\hline $\begin{array}{l}\text { Bundles }\left(\mathrm{gp} / \mu \mathrm{m}^{2}\right) \\
\text { Vesicles }(\mathrm{gp} / \mu \mathrm{m})\end{array}$ & $\begin{array}{c}233.33(27 \cdot 60) \\
0.79(0 \cdot 19)\end{array}$ & $\begin{array}{r}484.48(36.20)^{\star \star} \\
10 \cdot 19(0.99)^{\star \star \star}\end{array}$ \\
\hline
\end{tabular}

Values are mean (SEM) from at least 30 measurements performed on three animals from each experimental group. The significance of differences between control and ethanol treated groups was evaluated using the Student's $t$ test. $\star \star \mathrm{p}<0.01$ and $\star \star \star \mathrm{p}<0.001$ comparing values in both

experimental groups.
Specimen preparation and immunocytochemistry Three neonates from different litters in each experimental group were killed by decapitation kept in a thermostatically controlled humidity chamber at $37^{\circ} \mathrm{C}$ until death. 


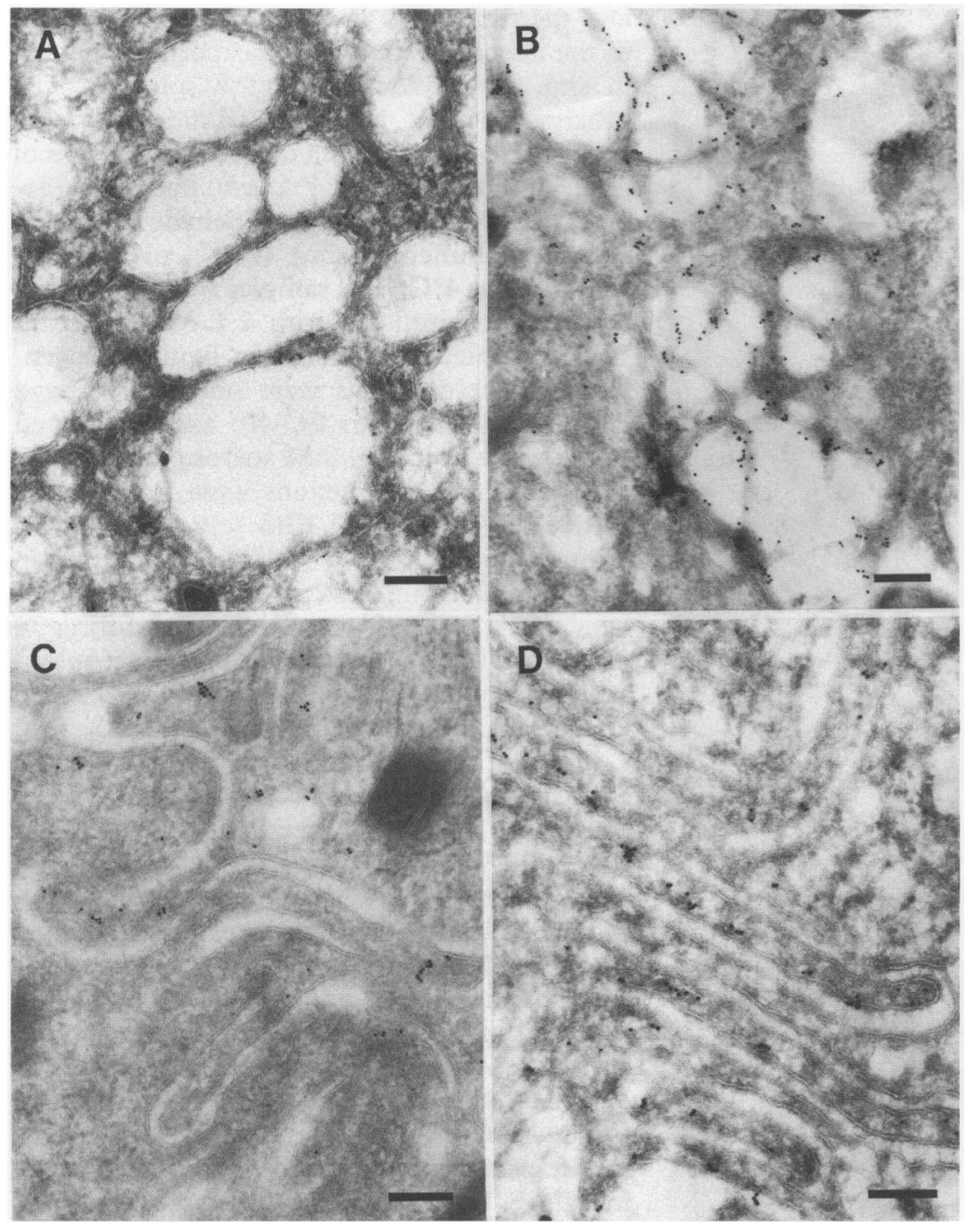

Figure 2: Actin immunolocalisation in control ( $A$ and $C$ ) and prenatally ethanol exposed enterocytes $(B$ and $D)$. Vesicular elements from apical and lateral enterocyte cytoplasm showed no labelling in controls $(A, \times 55000)$, whereas homologous areas in the ethanol exposed group were strongly labelled $(B, \times 53000)$. The lateral interdigitations between adjacent enterocytes were little developed and poorly labelled in controls $(C, \times 57000)$, whereas in the ethanol exposed group they were highly developed and labelled $(D, \times 62$ 000). Bars $=5 \mu \mathrm{m}$. cell (Bio-Rad Laboratories, Richmond, CA) in 5-12\% acrylamide gels under reducing conditions. Polypeptides were stained in the gels using Coomassie Blue R (Bio-Rad). Apparent molecular masses of polypeptides were determined from their relative mobilities compared with a standard of molecular mass protein (thyroglobulin, $330 \mathrm{kDa}$; bovine serum albumin, $67 \mathrm{kDa}$; catalase, $60 \mathrm{kDa}$; lactate dehydrogenase, $36 \mathrm{kDa}$, and ferritin $18.5 \mathrm{kDa}$ ).

After electrophoresis, polypeptides from SDS gels were equilibrated in $50 \mathrm{mM}$ TRIS$\mathrm{HCl}, \mathrm{pH} 7 \cdot 4$, in $20 \%$ glycerol for one hour ${ }^{31}$ and then transferred to nitrocellulose membranes $^{32}$ in carbonate blot buffer $(10 \mathrm{mM}$ $\mathrm{NaHCO}_{3}, 3 \mathrm{mM} \mathrm{Na} \mathrm{CO}_{3}, \mathrm{pH}, 9.9$, in $20 \%$ $\mathrm{MeOH})$. Transfer was achieved at $20 \mathrm{~V}$ overnight at $4^{\circ} \mathrm{C}$. Membranes were blocked with $3 \%$ ovalbumin in $10 \mathrm{mM}$ PBS for 30 minutes and then incubated either with the same mAb against cytokeratin used in the immunocytochemical techniques (diluted 1:20 000 in PBS with 1\% ovalbumin) or with rabbit antiubiquitin serum (Sigma, diluted $1: 300$ ) overnight at $4^{\circ} \mathrm{C}$. After three washes in $10 \mathrm{mM}$ PBS $0 \cdot 2 \%$ TWEEN 20 (Sigma) the membranes were incubated for two hours at room temperature with peroxidase conjugated rabbit antimouse (Ig or peroxidase conjugated swine antirabbit Ig (Dako, Glostrup, Denmark) depending on the primary antibody. The membranes were developed in a substrate solution of 3,3'-diaminobenzidine tetrahydrochloride (DAB, Sigma) as chromogen and recorded on Technical Pan film (Kodak, Hemel Hempstead, UK).

\section{Results}

Cytoskeletal immunolocalisation was performed in duodenum and proximal jejunum of both control and prenatally ethanol exposed newborn rats. Within each experimental group, absorptive cells from the duodenum were structurally similar to those of the proximal jejunum, and had the same organisation pattern as those of adults. However, prenatally ethanol exposed enterocytes showed greater development of endomembranes around the nucleus than controls. These membranes, which appeared in a vesicular form and associated with saccules of Golgi complex (see Figs 2,3 , and 4), were identified as trans golgi or trans golgi network (TGN) by specific labelling with anti- $\beta$ 1,4-galactosyl transferase (see Fig 4).

Tubulin was similarly distributed throughout the cytoplasm of control and prenatally ethanol exposed neonates, mainly in microtubular structures. No atypical intracellular localisation was seen such as label association with microvilli or TGN (Fig 1 (C) and (D)). The label density of the tubulin associated with cytoplasm showed no significant differences between control and prenatally ethanol exposed neonates (Table).

Actin distribution in the apical domain of the enterocyte was similar in control and prenatally ethanol exposed neonates (Fig 1 (A) and (B)), and actin label density in the 


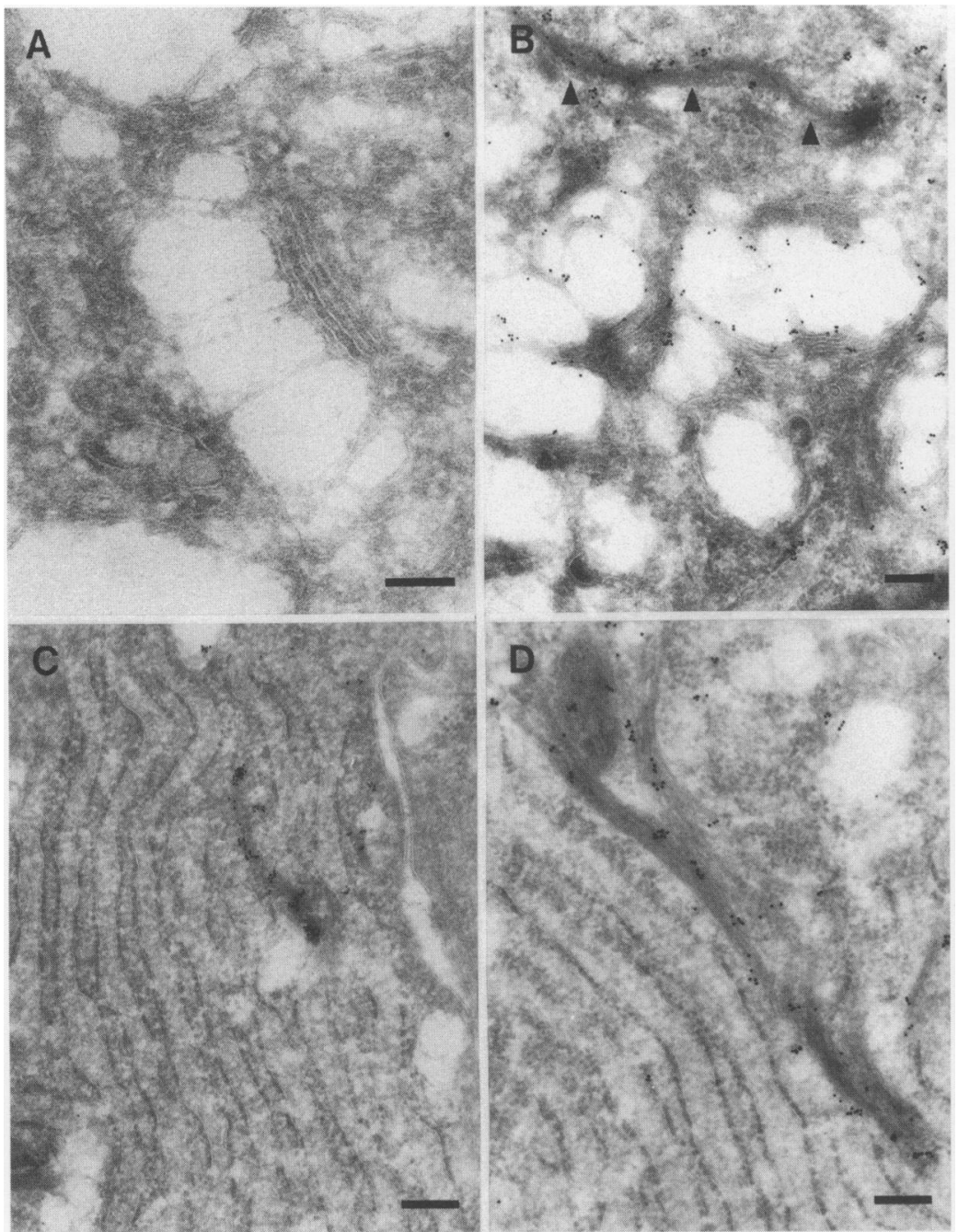

Figure 3: Cytokeratin immunolocalisation in control ( $A$ and $C$ ) and prenatally ethanol exposed enterocytes ( $B$ and $D)$. Golgi related vesicles were devoid of label in controls $(A, \times 63000)$, whereas in the ethanol exposed group they showed strong labelling associated with the inner face of vesicular membranes $(B, \times 45000)$. Cytokeratin bundles showed little label in controls $(C, \times 21000)$, whereas in the ethanol exposed group they showed abundant label $(D, \times 53000)$. Bars $(A, B, D)=5 \mu \mathrm{m} ;$ bar $(C)=2 \mu \mathrm{m}$.

microvilli showed no significant differences between experimental groups (Table). Likewise, the cytoplasmic bundles of actin filaments showed no quantitative or distribution differences between experimental groups (data not shown). However, the interdigitations in the lateral domain of plasma membrane were more developed in prenatally ethanol exposed neonates than controls (Fig 2 (C) and (D)), and the actin label density associated with these structures was significantly increased in ethanol exposed enterocytes (Table). Regarding the vesicular compartment, abundant actin label density was associated with the internal face of vesicular membranes in prenatally ethanol exposed enterocytes, whereas control vesicles were devoid of label, showing a label density similar to background (Fig 2 (A) and (B); Table).

Cytokeratin localisation at the terminal web and apical cytoplasm showed no significant differences between control and prenatally ethanol exposed enterocytes (Fig 3 (C) and (D)). However, the cytokeratin bundles from medial and basal cytoplasm showed a significant label density increase in prenatally ethanol exposed enterocytes, compared with controls
(Table). Furthermore, like actin, cytokeratin was associated with the vesicular compartment of prenatally ethanol exposed enterocytes, and absent in control vesicles (Fig 3 (A) and (B)).

Characterisation of this vesicular compartment with anti- $\beta$ 1,4-galactosyl transferase (Fig 4 (A)) showed that both actin (Fig 4 (B)) and cytokeratin (Fig $4(\mathrm{C})$ ), but not tubulin, were associated with the trans golgi or TGN compartments, or both, after prenatal ethanol exposure.

The protein pattern of intestinal cytoskeletal enriched fractions was similar in control and prenatally ethanol exposed neonates, as shown by SDS-PAGE analysis. However, a significant increase in polypeptides of molecular mass ranging from 39 to $54 \mathrm{kDa}$ was seen in prenatally ethanol exposed neonates (Fig 5 (A)), compared with controls. This result supports the data of immunogold quantifications (Table) as the increased protein range coincides with the molecular mass of most intestinal cytoskeletal proteins.

Western blotting of the intestinal cytoskeletal enriched fractions and subsequent analysis of cytokeratins with the same $\mathrm{mAb}$ as used for immunolocalisation, showed a similar cytoskeletal pattern for the two experimental groups within the range of $45-53 \mathrm{kDa}$ (Fig 5 (B)). However, an additional band of an apparent molecular mass of $28-29 \mathrm{kDa}$ was detected in the prenatally ethanol exposed neonates. It was noteworthy that none of the cytokeratins characterised so far in published reports have a molecular mass similar to 28-29 $\mathrm{kDa}$.

The increased abundance of ubiquitin in prenatally ethanol exposed neonates, compared with controls, was shown by western blotting of the intestinal cytoskeletal enriched fractions (Fig 6). This increase corresponds basically to the free ubiquitin pool.

\section{Discussion}

This study shows the effects of ethanol on the major cytoskeletal proteins of the gut epithelium from rat neonates, which was exposed to higher concentrations in the gastrointestinal lumen than in other fetal compartments. ${ }^{4}$ Ethanol crosses the placental barrier and is distributed and accumulated in a concentration gradient. ${ }^{43}$ However, reports of the passage of acetaldehyde, a product of ethanol oxidation, across the placental barrier are contradictory. ${ }^{34-37}$ Although placenta and fetal liver contain little alcohol dehydrogenase, ${ }^{436}$ there is evidence during longterm alcoholism of other pathways of ethanol oxidation both from maternal and from fetal tissues, ${ }^{38} 39$ which could interact with the cytoskeleton. These derivatives of ethanol, such as acetaldehyde and hydroxyethyl radicals, are probably produced either by peroxisomal catalase or by the microsomal ethanol inducible cytochrome P450. ${ }^{40}$ Furthermore, Lange ${ }^{41}$ reported the formation of ethyl esters by non-oxidative reactions associated with glutathione S-transferase.

Increased concentrations of actin and cytokeratins, but not tubulin, were first suggested 


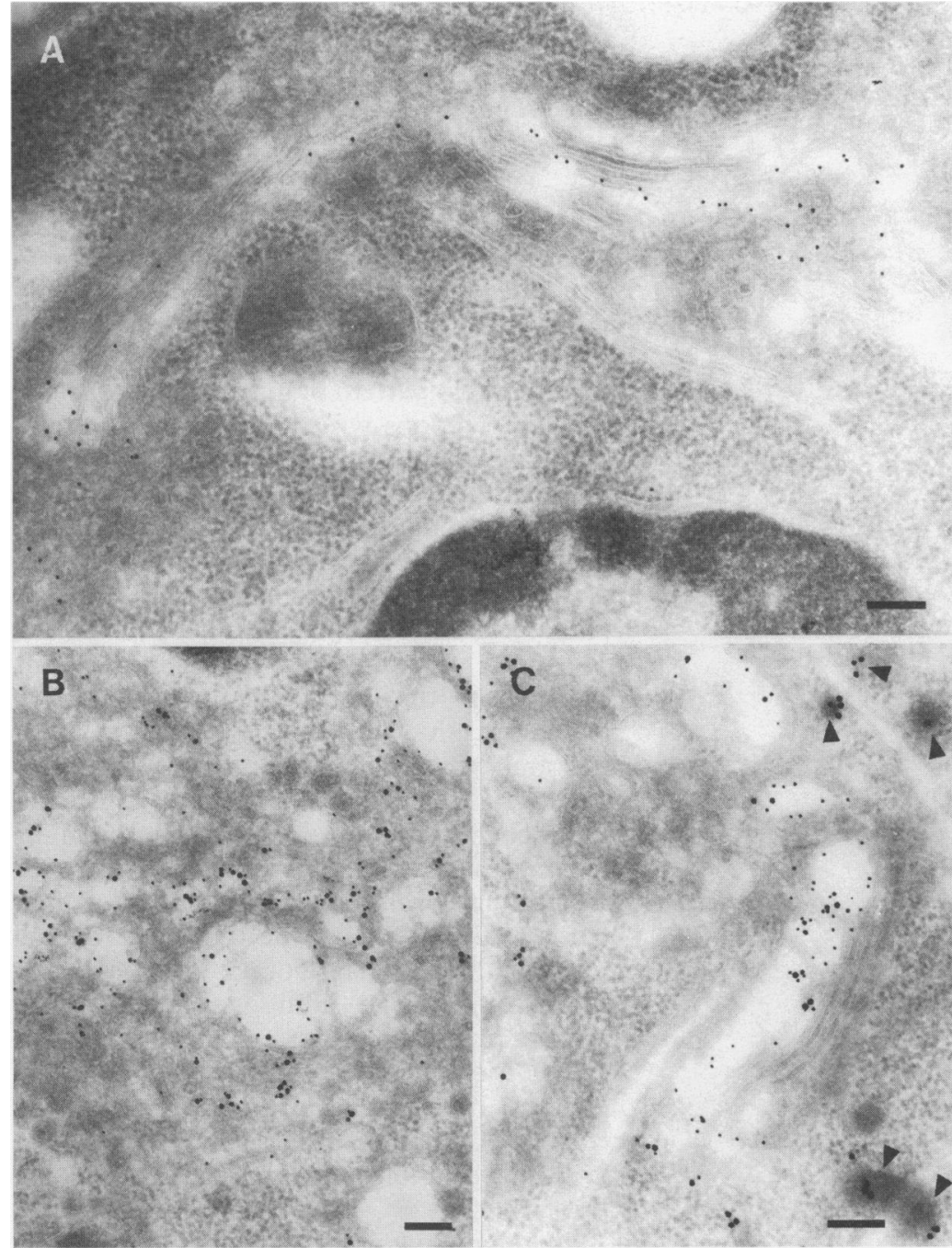

Figure 4: Positive control for the immunolocalisation of $\beta$ 1,4-galactosyl transferase, a marker for trans golgi and TGN $(A, \times 58000)$. Double immunostaining for $\beta 1,4-$ galactosyl transferase $(10 \mathrm{~nm}$ gold $)$ and either actin $(15 \mathrm{~nm}$ gold $)(B, \times 46000)$ or cytokeratin $(15 \mathrm{~nm}$ gold $)(C, \times 56000)$. The colocalisation shows the association of both actin and cytokeratin epitopes with the TGN membranes. Section $C$ illustrates both the dilatation of cytokeratin containing TGN vesicles and cytokeratin association with desmosomes (arrowheads). Bars $=5 \mu \mathrm{m}$.

by the labelling densities obtained in immunolocalisations of prenatally ethanol exposed enterocytes, compared with controls. Furthermore, this increase was confirmed by the increased protein abundance in the range of 39 to $54 \mathrm{kDa}$ found in SDS-PAGE analysis, as nearly all cytoskeletal proteins fall in this range. This cytoskeletal increase could be produced either by protein overexpression or by inhibition of protein degradation. With regard to the first possibility, Zern et al ${ }^{10}$ showed a considerable increase in albumin synthesis in hepatocytes of rats fed for one year with a diet in which $36 \%$ of energy came from ethanol, compared with control rats. This protein increase was caused by an increase in the steady state level of active albumin mRNA in the adult ethanol exposed liver. With regard to the small intestine of neonates, a 10 -fold to 15 fold increase in the values of lactase and intestinal alkaline phosphatase mRNAs was found after prenatal ethanol exposure. ${ }^{42}$ However, this increase was not correlated with a similar increase in the protein mass.

The possibility of an ethanol induced inhibition of protein degradation has been studied in

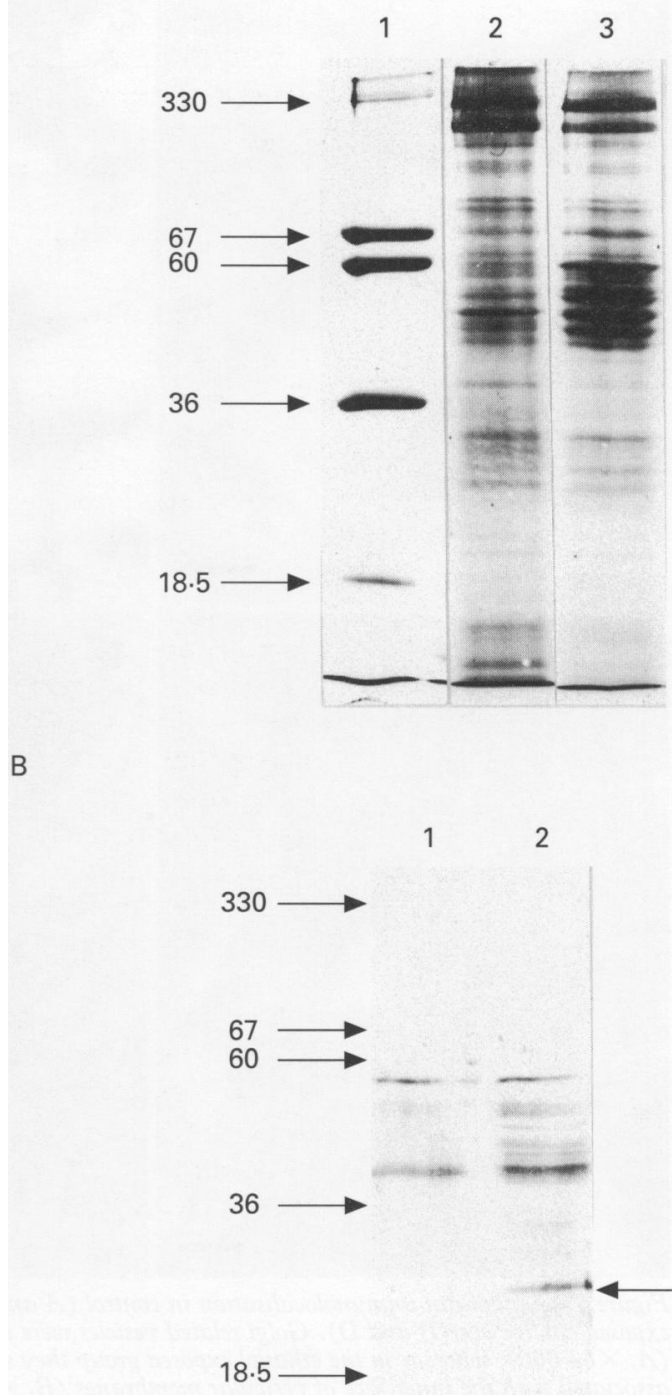

Figure 5: $(A)$ SDS-PAGE analysis of intestinal cytoskeleton enriched fractions (40 $\mu g$ /ane). Lane 1 corresponds to standard mass proteins. Lane 2 shows basal protein expression in control neonates. Lane 3 shows the overexpression in polypeptides ranging from 39-54 $k D a$ induced by prenatal ethanol exposure. (B) Western blot analysis of specific cytokeratins performed from the previous $S D S-P A G E$ as described in methods. Lane 1 shows control neonates; lane 2, prenatally ethanol exposed neonates. The blot confirms the overexpression of cytokeratins after prenatal ethanol exposure and shows a unique peptide of 28-29 kDa (arrowhead), which is a specific feature for the ethanol group.

the liver of adult alcohol fed rats. ${ }^{14}$ The volume densities of autophagosomes and autolysosomes in hepatocytes was lower in ethanol treated rats than controls. Moreover, the rate of proteolysis was decreased by $30 \%$ in ethanol treated rats, suggesting that ethanol feeding inhibits proteolysis in the adult liver by preventing the sequestration of protein into lysosomes. Western blotting of intestinal cytoskeletal enriched fractions showed a significant increase in ubiquitin in prenatally ethanol exposed neonates. Most of the ubiquitin increase can be attributed to the effect that ethanol exposure induces an increased gene expression of stress proteins. ${ }^{12}$ 


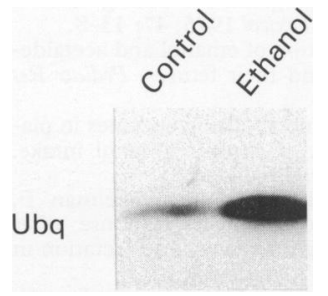

Figure 6: Western blot analysis of free ubiquitin
$($ (Ubq) in intestinal cytoskeletal enriched fractions.
On the other hand, Corsi et al ${ }^{43}$ showed that the cytoskeleton is covalently modified by ubiquitination. Furthermore, Akamatsu et al ${ }^{44}$ stated that ubiquitination is an important process in the degradation of intermediate filament proteins in the cytoplasm. However, our results showed that the increase in the cytokeratin ubiquinitation was not correlated with an increase in the cytokeratin degradation. Moreover, the results obtained from the ethanol treated group - that is, the increase in cytokeratin amount and the presence of the cytokeratin related polypeptide of $28-29 \mathrm{kDa}-$ suggest a defective degradation of the proteins. The increased reactivity that several cytoskeletal proteins exhibit for ethanol derivatives, especially aldehydes, could block the specific binding of ubiquitin, as both bind to lysine residues. ${ }^{184546}$

Furthermore, we observed that enterocytes exposed to ethanol in utero showed deficiencies in cell-cell and cell-basal lamina adhesion, with occasional detachment of the epithelial sheet (data not shown). This was in agreement with data of neural cell experiments in which addition of ethanol to the culture induced cell detachment. ${ }^{20}$ Ethanol in the culture medium interacted with the $\mathrm{L} 1$ and $\mathrm{N}-\mathrm{CAM}$ molecules of neurones resulting in inhibition of cell adhesion. In our study, the increased cytoskeletal components are actin and cytokeratins, which happen to be the elements that interact with the cell adhesion molecules of plasma membrane. Tubulin, on the other hand, is not increased after prenatal ethanol exposure, but it happens to be a cytoskeletal element unrelated to cell adhesion. We hypothesise that the presence of a high concentration of ethanol (an average of $30 \mathrm{mM}$ ) in the fetal gastrointestinal lumen ${ }^{4}$ would first result in covalent modifications of the surface adhesion molecules of enterocytes. Secondly, in response to loss of adhesiveness, feed back mechanisms would increase the expression of cell adhesion molecules, which might cause the overexpression and rearrangement of cytoskeletal elements.

The atypical localisation of actin and cytokeratin in the trans golgi or the TGN, or both, can only be explained by the molecular modifications caused by ethanol or its derivatives, or both, in both the cytoskeletal elements and the membrane of these compartments. Ethanol is a substrate for phospholipase $D,{ }^{16}$ an enzyme that catalyses the hydrolysis of phospholipids, such as phosphatidylcholine, to phosphatidic acids. However, this enzyme also utilises ethanol and several short chain alcohols as substrates, resulting in the formation of specific phosphatidylalcohols, such as phosphatidylethanol. Phosphatidylethanol induces an increase in the fluidity of artificial and natural bilayers, considerably modifying the physicochemical properties of membranes. ${ }^{15}$ Moreover, the hydrophobic head group of phosphatidylethanol might change the membrane architecture by disrupting the ionic bond lattice extending over the surface of the membrane. ${ }^{47}$ These molecular modifications of cellular membranes might facilitate the nonspecific entrance of altered proteins, actin, and cytokeratins, in the trans golgi or TGN, or both.

In conclusion, our findings suggest that ethanol in utero exerts severe changes in the cytoskeleton of the developing intestinal epithelium. Actin and cytokeratin are two affected components showing increased expression and atypical intracellular localisation. In contrast, tubulin is not affected. Therefore, the effects of ethanol in utero are specific for the cytoskeletal elements related with the plasma membrane and thus, affecting cell adhesion. These findings may contribute to understanding the cellular and molecular basis of intestinal dysfunctions found in the offspring of alcoholic mothers, causing pre and postnatal growth retardation.

The authors are grateful to Dr Senén Vilaró (Unitat de Biologia Cellular, Facultat de Biologia) for the serum against $\beta$ 1,4galactosyl transferase, to the staff of Serveis Cientifico-Tècnics (Universitat de Barcelona), and to Mr Robin Rycroft and Ms Mireia Martín for linguistic advice.

1 Buts JP, Sokal EM, Van Hoof F. Prenatal exposure to ethanol in rats, effects on postnatal maturation of the small intestine and liver. Pediatr Res 1992; 32: 574-9.

2 López-Tejero $\mathrm{MD}$, Arilla $\mathrm{E}$, Colás $\mathrm{B}$, Llobera $\mathrm{M}$, Herrera E. Low intestinal lactase activity in offspring from ethanol-treated mothers. Biol Neonate 1989; 55: 204-13.

3 Camps L, Kedinger M, Simon-Assmann P, López-Tejero MD. Effect of prenatal exposure to ethanol on intestinal development of rat fetuses. $\mathcal{F}$ Pediatr Gastroenterol Nutr (in press).

4 Través $\mathrm{C}$, Camps L, López-Tejero MD. Liver alcohol dehydrogenase activity and ethanol levels during chronic ethanol intake in pregnant rats and their offspring. Pharmacol Biochem Behav 1995; 52: 93-9.

5 Gottlieb TA, Ivanov IE, Adesnik M, Sabatini DD. Actin microfilaments play a critical role in endocytosis at the apical but not the basolateral surface of polarized epithelial cells. F Cell Biol 1993; 120: 695-710.

6 Peterson MD, Bement WM, Mooseker MS. An in vitro model for the analysis of intestinal brush border assembly: II changes in expression and localization of brush border assembly in Caco-2BBe cells. $\mathcal{F}$ Cell Sci 1993; 105: 461-72.

7 Mays RW, Beck KA, Nelson WJ. Organization and function of the cytoskeleton in polarized epithelial cells: a component of the protein sorting machinery. Curr Opin Cell Biol nent of the protein

8 Reddy YS, Beesley RC. Effects of acute and chronic ethanol on cardiac contractile protein ATPase activity of Syrian hamsters. Biochem Med Metab Biol 1990; 44: 259-65.

9 Guasch R, Renau-Piqueras J, Guerri C. Chronic ethanol consumption induces accumulation of proteins in the liver Golgi apparatus and decreases galactosyltransferase activity. Alcohol Clin Exp Res 1992; 16: 942-8.

10 Zern MA, Chakraborty PR, Ruiz-Opazo N, Yap SH, Shafritz DA. Development and use of a rat albumin cDNA clone to evaluate the effect of chronic ethanol administration on hepatic protein synthesis. Hepatology 1983; 3: 317-22.

11 Mochly-Rosen D, Chang F-H, Cheevers L, Kim M, Diamond I, Gordon AS. Chronic ethanol causes heterolDiamond I, Gordon AS. Chronic ethanol causes heterol-

12 Miles MF, Díaz JE, DeGuzman V. Ethanol-responsive gene expression in neural cell cultures. Biochem Biophys Acta 1992; 1138: 268-74.

3 Hu G, Querimit LA, Downing LA, Charness E. Ethanol differentially increases $\beta$-adrenergic and muscarinic acetylcholine receptor gene expression in NG108-15 cells. f Biol Chem 1993; 268: 23441-7.

14 Pösö AR, Hirsimäki P. Inhibition of proteolysis in the liver by chronic ethanol feeding. Biochem f 1991; 273: 149-52.

15 Omodeo-Salé F, Lindi C, Palestini P, Masserini M. Role of phosphatidylethanol in membranes. Effects on membrane phosphatidylethanol in membranes. Effects on membrane fluidity, tolerance to ethanol, and activity of memb
bound enzymes. Biochemistry 1991; 30: 2477-82.

16 Hoek JB, Thomas AP, Rooney TA, Higashi K, Rubin E. Ethanol and signal transduction in the liver. FASEB $\dot{f}$ 1992; 6: 2386-96.

7 Doyle KM, Bird DA, Al-Salihi S, Hallaq Y, Cluette-Brown $\mathrm{J}$, Gross KA, et al. Fatty acid ethyl esters are present in human serum after ethanol ingestion. $\mathcal{F}$ Lipid Res 1994; 35: 428-37.

18 Xu DS, Jennett RB, Smith SL, Sorrell MF, Tuma DJ. Covalent interactions of acetaldehyde with the actin/microfilament system. Alcohol Alcoholism 1989; 24: 281-9.

19 Niemelä O, Juvonen T, Parkkila S. Immunohistochemical demonstration of acetaldehyde-modified epitopes in human liver after alcohol consumption. $\mathcal{F}$ Clin Invest 1991; 87: 1367-74.

20 Charness ME, Safrans RM, Perides G. Ethanol inhibits neural cell-cell adhesion. F Biol Chem 1994; 269: 9304-9. 
21 Sáez R, Burgal M, Renau-Piqueras J, Marqués A, Guerri C. Evolution of several cytoskeletal proteins of astrocytes in primary culture: effect of prenatal alcohol exposure. Neurochem Res 1991; 16: 737-47.

22 Barbatis C, Morton J, Woods JC, Burns J, Bradley J, McGee J O'D. Disorganisation of intermediate filament structure in

23 Pinazo-Durán MD, Renau-Piquras J, Guerri C. Developmental changes in the optic nerve related to ethanol consumption in pregnant rats: analysis of the ethanol consumption in pregnant rats: analysis of the

24 Adickes ED, Mollner TJ. Ethanol-induced cytoskeletal dysgenesis with dietary protein manipulations. Alcohol Alcoholism 1986; 21: 347-55.

25 Testar X, López-Tejero MD, Llobera M, Herrera E. Ethanol administration in the drinking fluid to pregnan rats as a model for the fetal alcohol syndrome. Pharmacol Biochem Behav 1986; 24: 625-30.

26 Griffiths G, Simons K, Warren G, Tokayasu KT Immunoelectron microscopy using thin, frozen sections: application to studies of the intracellular transport of applicatikit to 1983; 96: 435-50.

27 Geuze HJ, Slot JW, van der Ley PA, Scheffer RCT, Griffith JM. Use of colloidal gold particles in double-labelling immunoelectron microscopy of ultrathin frozen tissue sections. F Cell Biol 1981; 89: 653-65.

28 Tokuyasu KT. Immunocytochemistry on ultrathin sections. Histochem $\mathcal{F}$ 1980; 12: 381-403.

29 Griffiths G, Hoppeler H. Quantitation in immunocytochemistry: correlation of immunogold labeling to absolute number of membrane antigens. F Histochem Cytochem 1986; 34: 1389-98.

30 Weibel ER. Stereological methods. Vol I. Practical methods for biological morphometry. New York: Academic Press, 1979.

31 Quaroni A, Calnek D, Quaroni E, Chandler JS. Keratin expression in rat intestinal crypt and villus cells. $\mathcal{f}$ Biol Chem 1991; 266: 11923-31.

32 Towin H, Staehelin T, Gordon J. Electrophoretic transfer of proteins from polyacrylamide gels to nitrocellulose sheets: procedure and some applications. Proc Natl Acad Sci USA 1979; 76: 4350-4.

33 Guerri C, Sanchis R. Acetaldehyde and alcohol levels in pregnant rats and their fetuses. Alcohol 1985; 2: 267-70.

34 Kesäniemi YA, Sippel HW. Placental foetal metabolism and acetaldehyde in rat. I. Content of ethanol acetaldehyde in placenta and foetus of the pregnant rat during ethanol intoxication. Acta Pharmacol Toxicol 1975; 47: 43-8.

35 Zorzano A, Herrera E. Disposition of ethanol and acetaldehyde in late pregnant rats and their fetuses. Pediatr Res 1989; 25: 102-6.

36 Sanchis R, Guerri C. Alcohol-metabolizing enzymes in placenta and fetal liver: effects of chronic ethanol intake. Alcohol Clin Exp Res 1986; 10: 39-44.

37 Gordon BHJ, Baraona E, Miyakawa H, Finkelman F, Lieber CS. Exaggerated acetaldehyde response after ethanol administration during pregnancy and lactation in rats. Alcohol Clin Exp Res 1985; 9: 17-22.

38 Cambon-Gros G, López-Tejero MD, Fernández $\mathrm{Y}$ Vilarem G, Mitjavila S. Increase in the $\mathrm{CCl}_{4}$ radical induced effects on the rat liver microsoms after chronic ethanol intake during gestation. In: Nordmann $R$, Ribière $\mathrm{C}$, Rouach H, eds. Advances in the Biosciences. Vol 71 Great Britain: Pergamon Press, 1988: 159-63.

39 Terada N, Nakai T, Yamaguchi M, Hatta A, Arizono K, Ariyoshi T. Effects of maternal ethanol intake during pregnancy on fetal and maternal liver enzymes systems in Wistar rats. 7 Pharmacobiodyn $1982 ; 5: 49-54$.

40 Lieber CS. Biochemical mechanisms of alcohol-induced hepatic injury. Alcohol Alcoholism 1991; suppl 1: 283-90.

41 Lange LL. Mechanism of fatty acid ethyl ester formation and biological significance. Ann NY Acad Sci 1991; 625: 802-5.

42 Estrada G, Krasinski SD, Montgomery RK, Grand RJ, García-Valero J, López-Tejero MD. Quantitative analysis of lactase-phlorizin hydrolase expression in the absortive enterocytes of newborn rat small intestine. $\mathcal{f}$ Cell Physiol (in press)

43 Corsi D, Galluzzi L, Crinelli R, Magnani M. Ubiquitin is conjugated to the cytoskeletal protein $\alpha$-spectrin in mature erythrocytes. I Biol Chem 1995; 270: 8928-35.

44 Akamatsu M, Hori S, Tsutsumi Y, Yoshiyuki R, Ohkido M. Ubiquitinated cytokeratin inclusions in lichen amyloidosus: an immunohistochemical analysis. Pathol Int 1995; 45: $116-22$.

45 Gregori L, Marriott D, West CM, Chau V. Specific recognition of calmodulin from Dictyostelium discoideum by the ATP, ubiquitin-dependent degradative pathway. f Biol Chem 1985; 260: 5232-5.

46 Rechsteiner $M$. Ubiquitin-mediated pathways for intracellular proteolysis. Ann Rev Cell Biol 1987; 3: 1-30.

47 Boggs JM. Lipid intermolecular hydrogen bonding: influence on structural organization and membrane function. Biochem Biophys Acta 1987; 906: 353-7. 